\title{
Formação de professores: a didática acerca da abordagem dos direitos humanos pelo educador como formador de cidadãos
}

\author{
Teacher training didactics on the approach to human rights by the educator an educator of citizen \\ Formación docente: didáctica sobre el abordaje de los derechos humanos por parte del educador
} como educador de ciudadanos

Recebido: 01/09/2021 | Revisado: 08/09/2021 | Aceito: 11/09/2021 | Publicado: 13/09/2021

\author{
Denise da Costa Dias Scheffer \\ ORCID: https://orcid.org/0000-0002-1755-542X \\ Universidade de Cruz Alta, Brasil \\ E-mail: dcdscheffer@gmail.com
}

\begin{abstract}
Resumo
A formação de professores perfaz o caminho para a construção do desenvolvimento social dos sujeitos através da educação, na tratativa acerca das concepções formativas no campo social para a cidadania, oriunda ao sujeito de direitos e deveres. O objetivo do artigo é analisar a fundamentalidade das premissas normativas e garantidoras do direito a educação, da construção dos saberes aliados aos direitos humanos e a preparação de profissionais para a formação cidadã. A metodologia adotada para a pesquisa foi de natureza qualitativa, do tipo descritiva, pautada em doutrinas pertinenetes a temática e legislações vigentes para o aprofundameto da reflexão. Na contemporaneidade, o debate acerca do contexto educacional perfaz suma importância para as didáticas de ensino e a formação cidadã, em prol da dignidade da pessoa humana, preceito dos direitos humanos, embasados na abordagem emancipatória dos sujeitos, na campo social das vivências coletivas, para a consolidação da valorização dos valores diretivos elencados na Declaração Universal dos Direitos Humanos e afirmados na Constituição Federal de 1988, com preceito garantidor para a educação através da Lei de Diretrizes e Bases da Educação Nacional.
\end{abstract}

Palavras-chave: Educação; Sujeitos; Formação; Cidadania.

\begin{abstract}
The training of teachers makes up the path for the construction of the social development of subjects through education, dealing with the formative conceptions in the social field for citizenship, arising from the subject of rights and duties. The aim of the article is to analyze the fundamentality of the normative and guaranteeing premises of the right to education, the construction of knowledge allied to human rights and the preparation of professionals for citizenship education. The methodology adopted for the research was of a qualitative nature, of the descriptive type, based on doctrines pertinent to the theme and current legislation for the deepening of reflection. Nowadays, the debate about the educational context is of paramount importance for teaching didactics and citizen education, in favor of the dignity of the human person, the precept of human rights, based on the emancipatory approach of subjects, in the social field of collective experiences, to the consolidation of the valorization of the directive values listed in the Universal Declaration of Human Rights and affirmed in the Federal Constitution of 1988, with a guaranteeing precept for education through the Law of Guidelines and Bases for National Education.
\end{abstract}

Keywords: Teaching; Knowledge; Activities; Experiences.

\begin{abstract}
Resumen
La formación del profesorado es la forma de construir la educación, abordando las concepciones formativas en el ámbito social para la ciudadanía, que surgen desde la asignatura de derechos y deberes. El objetivo del artículo es analizar la fundamentalidad de las premisas normativas y garantizadoras del derecho a la educación, la construcción de saberes aliados a los derechos humanos y la preparación de profesionales para la educación ciudadana. La metodología adoptada para la investigación fue de carácter cualitativo, de tipo descriptivo, basada en doctrinas pertinentes al tema y legislación vigente para la profundización de la reflexión. En la actualidad, el debate sobre el contexto educativo es de suma importancia para la enseñanza de la didáctica y la educación ciudadana, a favor de la dignidad de la persona humana, precepto de los derechos humanos, a partir del enfoque emancipador de los sujetos, en el ámbito social de las experiencias colectivas., a la consolidación de la valorización de los valores rectores recogidos en la Declaración Universal de Derechos Humanos y afirmados en la Constitución Federal de 1988, con precepto garante de la educación a través de la Ley de Lineamientos y Bases para la Educación Nacional.
\end{abstract}

Palabras clave: Educación; Asignaturas; Formación; Ciudadanía. 


\section{Introdução}

Diante das prerrogativas legais elencadas na Lei das Diretrizes e Bases da Educação Nacional, norteadoras da condução educacional, na busca da consolidação formativa de direitos e deveres dos indivíduos, na constituição do cidadão e da base de aprendizado mensurado no ambiente escolar, há de se mencionar a formação de professores como estrutura primordial para a afetiva construção e transmissão do ensino e da aprendizagem, do estudo dos direitos humanos e seu conteúdo garantidor da dignidade da pessoa humana.

O objetivo do artigo é analisar a fundamentalidade das premissas normativas e garantidoras do direito a educação, acerca da legislação educacional, imbricadas a didática de ensino e aprendizagem através dos direitos enfatizados no texto da Declaração Universal dos Direitos Humanos, para a reflexão na formação de professores e aplicabilidade didática que os profissionais da educação transcendem aos educandos afim de construir os saberes na formação social dos sujeitos, na condução das vivências coletivas e sociais para a cidadania.

O tema formação cidadã, perfaz constante movimento de pesquisas acerca da formação social do sujeito no ambiente escolar, a educação apresenta-se como premissa fundamental para a construção de saberes acerca da igualdade, da inclusão e da diversidade, sendo que a estruturação da formação social do aluno a partir da base qualificadora e pedagógica do professor e de que forma sua didática se consolida nessa formação cidadã e diante da imersão do conhecimento dos direitos humanos universais.

O universo escolar, consolida-se como formador de estruturas cidadãs, do meio social, evidencia o ambiente educacional como base de ensino e aprendizagem, o professor como agente social de destaque na responsabilização formadora do indivíduo, na transmissão dos saberes, assumindo seu papel de direcionador do contexto escolar, com enfoque primordial em sua busca por aprendizado, sua formação acadêmica e científica com êxito na busca por respostas a anseios determinantes a construção da vida em sociedade, dos indivíduos capazes de relacionar-se em direitos e deveres e da construção do coletivo social, baseado na inclusão da diversidade e na igualdade a todos.

\section{Metodologia}

O desenvolvimento da pesquisa perfaz a busca bibliográfica de natureza qualitativa, de acordo Minayo (2012), as pesquisas qualitativas são, geralmente, utilizadas nas pesquisas sociais, possibilitando uma abrangência de conhecimentos no tocante da sociedade. Importante salientar que a pesquisa científica contribui para o engrandecimento em prol do conhecimento aos sujeitos e pode ser auferido de diversas maneiras, como enfatizam Pereira et al. (2018, p.13), o conhecimento pode ser adquirido de diversas formas: sensação, percepção, imaginação, memória, linguagem, raciocínio e intuição.

Portanto, interpretar os saberes adquiridos na pesquisa conduz a construção do desenvolvimento dos sujeitos para os saberes, pautado na qualidade do embasamento teórico doutrinário e qualitativo das bibliografias abordadas, nas palavras de Marconi e Lakatos (2004, p.269), a metodologia qualitativa preocupa-se em analisar e interpretar aspectos mais profundos, descrevendo a complexidade do comportamento humano. Permeando desta forma a busca dos saberes sociais no campo da coletividade.

\section{Resultados e Discussão}

As tratativas acerca da pedagogia de ensino e aprendizagem imbricadas ao ambiente escolar interagem ao longo da trajetória social nas relações humanas dos sujeitos, os ensinamentos manifestam-se diariamente na vida em sociedade, diante do exposto, afirma Freire (2001, p.12), a educação é permanente na razão, de um lado, da finitude do ser humano, de outro, da 
consciência que ele tem de sua finitude, aliando-se dessa forma a consolidação do autor a premissa educacional inovadora e liberal de fluxo contínuo.

O ensino e aprendizado manifestam-se nesse momento, a criação da televisão, avanços industriais e as relações da humanidade com novidades tecnológicas foram unidas a conceitos educacionais e ao manejo das relações no ambiente educacional. Nas palavras de Brandão (1981, p.21-22), um dos pressupostos do método é a ideia de que ninguém educa ninguém e ninguém se educa sozinho. Desta forma, a diversidade de didáticas se manifesta desta forma por incluir o social e o igualitarismo no ambiente escolar, nas relações culturais e sociais, emanadas historicamente também do século XXI.

Fazendo menção bibliográfica a uma das autoridades pedagógicas acerca da pesquisa em educação e sua abordagem da acerca da formação de professores, cita-se a explanação de Cattani (2011, p.30):

A obra de António Nóvoa possui o atributo de fazer proliferar nossas ideias e questões - e é bem provável que esta seja uma das razões principais que ajudem a compreender a intensidade de sua presença nas reflexões educacionais contemporâneas, especialmente, mas não apenas, em Portugal e no Brasil. Seus escritos incidem sobre vários problemas da pedagogia e investigam territórios diversos no campo educacional: a história da educação e a formação dos professores têm sido objetos de seus trabalhos mais conhecidos em nosso país.

Os padrões educacionais atuais, são baseados nas transformações ocorridas no século XIX, período de grande transição em padrões de aprendizado, liberdades de práticas religiosas e ofícios relativos a profissionalização e democracia e a criação e afirmação dos direitos humanos, permitindo desta forma a construção dos saberes através das relações sociais dos sujeitos, pautado nas normativas coletivas de convivências e no respeito mútuo para o desenvolvimento social da sociedade.

Seguindo ainda a menção as mesmas ideias e inspiração de Antônio Nóvoa, cumpra-se mencionar o conceito de Boto (2018, p.3):

Um dos maiores especialistas internacionais no campo da História da educação, António Nóvoa também se notabilizou no campo da Educação Comparada e no território do que poderíamos compreender por história da formação docente. É autor de referência nos estudos a respeito de políticas educativas, especialmente aquelas desenvolvidas pela União Europeia. É reputado como um dos maiores conhecedores do repertório da área da educação, tendo absoluto reconhecimento internacional, especialmente na Europa e nas Américas do Norte e do Sul.

Desta forma, direitos humanos, foram debatidos e consolidados após as Segunda Guerra Mundial e oficialmente regulamentados no ano de 1948, a partir da Declaração Universal dos Direitos Humanos. Portanto, a Declaração Universal dos Direitos Humanos trata-se de um pacto de cumprimento de direitos coletivos, opcionalmente usufruído por países que queiram aderir a suas cláusulas, no intuito de resguardar a dignidade da pessoa humana e seus direitos individuais.

Delimitando alguns artigos de acordo com a temática da Declaração Universal dos Direitos Humanos (1948), tem-se o exposto:

Artigo 1- Todo ser humano tem capacidade para gozar os direitos e as liberdades estabelecidos nesta Declaração, sem distinção de qualquer espécie, seja de raça, cor, sexo, idioma, religião, opinião política ou de outra natureza, origem nacional ou social, riqueza, nascimento, ou qualquer outra condição.

Artigo 26 - Todo ser humano tem direito à instrução. A instrução será gratuita, pelo menos nos graus elementares e fundamentais. A instrução elementar será obrigatória. A instrução técnico-profissional será acessível a todos, bem como a instrução superior, está baseada no mérito.

A formação de indivíduos faz parte da premissa da educação, ela está presente no cotidiano escolar, na vida em sociedade e nas relações familiares, a inclusão do diverso ou do diferente faz parte do processo de evolução da história, 
importante fazer parte da modernização de conceitos profissionais e educacionais promovem debates entre na sociedade, sobre ensinamentos voltados a construção da formação cidadã dos indivíduos. A inclusão do aprendizado dos direitos humanos consolida o embasamento dos saberes da vida social de direitos e deveres na sociedade e da seguridade legal proclamada na Declaração Universal dos Direitos Humanos.

De acordo com Boaventura (2009 p.6), sobre o conceito de direitos humanos assenta num bem-conhecido conjunto de pressupostos, todos claramente ocidentais e facilmente distinguíveis de outras concepções de dignidade humana em outras culturas. Portanto para incluir valores e conceitos sociais de igualdade e diversidade entre os povos, é preciso refletir e comunicar-se com outros profissionais através de sua formação profissional e tornando assim causadores da transmissão de saberes e na manifestação dos temas abordados acerca da ótica dos direitos humanos, promovendo dessa forma o contato entre as pessoas e suas formas de relacionamentos como aprendizado coletivo e diverso, baseado em valores éticos e morais e ainda sociais na vida em sociedade.

Acerca da discussão do tema, acerca do posicionamento conceitual da profissão de educador/professor, é possível refletir a contemporaneidade da atuação profissional, carregando mudanças ao longo dos anos, tramitando nos diversos métodos de ensino e aprendizagem que se desenvolvem no decorres das mudanças históricas de vivencias entre os sujeitos, como expõe o autor Perrenoud (2000, p.26), onde indaga que, o professor dispende energias para criar novas e eficazes situações de aprendizagem, encaradas contemporaneamente como amplas, abertas, carregadas de sentido e regulação.

De acordo com as concepções de Nóvoa (2018, p.10), a reflexão acerca da definição da jornada de trabalho de um professor, através de listas intermináveis de competências, cuja simples enumeração se torna insuportável, mas sim elencar tais competências e apontamentos que determinam a atividade docente na sociedade e principalmente as constantes transformações que docência sofreu no decorrer dos tempos. Desta forma, deve-se haver um olhar em especial para o profissional educador, portador do conhecimento para transpor o ensino ao coletivo.

Segundo Moran (2015, p.02), a aprendizagem necessita constantemente de movimento e esse em formato colaborativo:

Num sentido amplo, toda a aprendizagem é ativa em algum grau, porque exige do aprendiz e do docente, formas diferentes de movimentação interna e externa, de motivação, seleção, interpretação, comparação, avaliação, aplicação. Aprendemos também de muitas maneiras, com diversas técnicas, procedimentos, mais ou menos eficazes para conseguir os objetivos desejados.

Sobre esse ideal de formação didática profissional, Gagotti (2009, p.9), explica que, aprender a viver juntos - a viver com os outros. Compreender o outro, desenvolver a percepção da interdependência, da não-violência, administrar conflitos. Descobrir o outro, participar de projetos comuns. Ter prazer no esforço comum. Participar de projetos de cooperação. Essa é a tendência. Segundo Libanêo (2013, p.01), aliado a formação de professores, deve-se haver o planejamento escolar, na dizimação dos conteúdos, o planejamento é um meio para programar as ações docentes, mas é também um momento de pesquisa e reflexão [...]

Cabe ressaltar que a escola é o ambiente de troca de pensamentos e valores, trazidos de forma individual e construídos com base coletiva, ressaltando a importância da igualdade de todos, sendo essa explicitada em texto de lei ou baseada no respeito dos direitos e deveres habituais, e o ambiente escolar aliado aos aprendizado dos direitos humanos busca promover essa importante aliança de conhecimento, estando primeiramente capacitado o profissional da educação para a efetiva transposição dos saberes aos alunos.

Sobre a atribuição estudantil da escola, pertinente ressaltar Mariani (2009, p.10), a compreensão de educação para além de uma proposta baseada na racionalidade técnico-instrumental, com ênfase na preparação para o exercício da cidadania podem ser encontrados no objetivo geral da escola. Segue que a escola é o ambiente estruturador da formação social do aluno e 
o professor é o mestre direcionador desse caminho, provocador do ensino e aprendizagem e estruturador das concepções sociais dos cidadãos ali preparados para o mercado de trabalho e vida de direitos e deveres.

Seguindo ainda o enfoque da participação da escola na construção dos preceitos cidadãos, cita-se Cortella (2016):

A função da escola é, acima de tudo, a formação de natureza técnico-científica cidadã. É escolarizar, isto é, oferecer ferramentas que a cultura letrada carrega dos vários campos da atividade humana para uma cidadania de convivência. Não é tarefa das escolas, de maneira nenhuma, assumir o conjunto de educação de jovens e crianças, confundindo escolarização com educação. Educação é a formação integral de uma pessoa, que compete à família; escolarização, um pedaço da educação, este sim pertinente à escola, o qual deve ser partilhado com instituições sociais, poder público, mídia e, claro, com a própria família. Nós, professores, ajudamos no conjunto de educação, sendo nossa parte escolarizar. Não se trata de reduzir nosso campo de atuação, mas é importante esclarecer para que não obtenhamos frustração. Professor escolariza.

Obstante citar o processo de formação de professores e sua importância, tendo em vista a grandiosidade da efetiva profissionalização dos professores e preparação para o fornecimento de saberes aos alunos, sua devida base de conhecimento e explanação de seu âmbito profissional e ainda a colocação didática na formação de cidadãos detentores de ensino e aprendizado. Seguindo a premissa da educação autônoma de Paulo Freire, patrono da educação no Brasil, símbolo da liberdade do ensino e da formação de professores dinâmicos diante da diversidade, inclusão e igualdade, refletindo acerca da importância do educador como ferramenta de enlace no meio educacional.

De encontro a formação de professores e sua importância no ambiente escolar, importante ressaltar a colocação de Vasconcelos (2018, p.10). Com esse intuito, a criação do formar possibilita nossa própria reinvenção como professoras, pesquisadoras e formadoras de professores. No ambiente educacional deve-se haver constantes debates, provocações e trocas de saberes, visando a construção do conhecimento de forma significativa e que inter-relacione questões históricas, políticas, culturais, sociais, ambientais e econômicas (Silveira, Lorenzetti, Scheffer e Golle, 2021).

Pertinente elencar que diante da magnitude profissional transmissora de saberes dos professores, cabe ao processo de formação de professores, preparar os profissionais a realidade do ambiente escolar, a efetiva transmissão do conhecimento e a busca constante pela apropriada consolidação da educação para a emancipação dos sujeitos na trajetória individual de seus direitos e deveres para a convivência na coletividade.

Correlatando ainda a reflexão de Freire (2001, p.259 e 260), acerca do educador e sua profissionalização formativa:

A responsabilidade ética, política e profissional do ensinante lhe coloca o dever de se preparar, de se capacitar, de se formar antes mesmo de iniciar sua atividade docente. Esta atividade exige que sua preparação, sua capacitação, sua formação se tornem processos permanentes. Sua experiência docente, se bem percebida e bem vivida, vai deixando claro que ela requer uma formação permanente do ensinante. Formação que se funda na análise crítica de sua prática.

Portanto, promover o debate acerca da formação de professores, o ensino dos direitos humanos, pautado na narrativa constitucional na formação dos sujeitos de direitos e deveres, perfaz o construção no campo social dos valores éticos e morais, em prol da efetiva consolidação da garantia prática da dignidade da pessoa, respeitando as relações interpessoais nas diretrizes coletivas de cidadania aos sujeitos para a vida em sociedade.

\section{Conclusão}

O objetivo do artigo em analisar as diretrizes normativas evidenciadas na legislação educacional, imbricadas acerca da Declaração Universal dos Direitos Humanos, na formação de professores, responsáveis pelo ensino e aprendizagem no campo da educação transcendem aos educandos afim de construir o debate dos saberes para a didática de ensino na construção da 
formação social do cidadão, permitindo assim o caminho para novos debates acerca da temática, para a formação de professores no campo da cidadania, permeando o desenvolvimento social dos sujeitos.

A relevância da temática da formação cidadã, refletida através da pesquisa, demonstra a importância acerca discussão no campo da educação, e seus atores dominantes, com um direcionamento único, a propagação do ensino e aprendizagem, justificando desta forma resultados basilares acerca da pesquisa para a relevância no campo dos saberes, na construção do aprendizado, na transmissão didática da tema de direitos humanos, a partir da constituição do profissional professor, respaldado nas concepções pedagógicas sociais da cidadania, na formação dos sujeitos para as relações humanas embasadas no respeito, na dignidade da pessoa e no exercício da cidadania.

$\mathrm{Na}$ contemporaneidade, se faz necessário a constância dos debates acerca da temática da dignidade da pessoa, aos preceitos entrelaçados no campo da educação para o ensino e aprendizagem, imbricados a didática metodológica da transposição dos saberes desenvolvidas a partir da formação de professores, perfazendo a construção de novos conhecimentos deixando como sugestão para novas pesquisas a fim de contribuir na reflexão para a formação cidadã dos sujeitos, oriunda da formação de professores e sua didática de ensino.

\section{Agradecimentos}

De forma especial, agradeço a Coordenação de Aperfeiçoamento de Pessoal de Nível Superior - CAPES, pelo oferecimento de bolsa de estudos de pós-graduação nível mestrado a mim concedida. Com certeza este fomento se dá de forma essencial acerca da preparação para docência, além da construção da jornada para a pesquisa científica, engrandece o desenvolvimento do viés científico e auxilia novos aprofundamentos acerca da temática abordada.

\section{Referências}

Boto, C. (2020). António Nóvoa: uma vida para a educação. https://www.scielo.br/pdf/ep/v44/1517-9702-ep-44-e201844002003.pdf.

Brandão, C. R. (1981). O que é Método Paulo Freire. Editora Brasiliense.

Cattani, A. D. (1996). Trabalho e autonomia. Vozes.

Cortella, M. S. (2016). Professor tem de buscar a formação das famílias. https://www.cpp.org.br/informacao/entrevistas/item/9160-professor tem-de-buscar-aformacao-das-familias-diz-cortella.

Declaração Universal dos Direitos Humanos (1948). Assembleia Geral das Nações Unidas em Paris. https://www2.senado.leg.br/bdsf/bitstream/handle/id/ 508144/000992124.pdf

Freire, P. (2001). Política e Educação. (6a ed.), Cortez.

Gadotti, M. (1992). Diversidade cultural e educação para todos. Graal.

Lei Nº 9.394, de 20 de Dezembro de 1996 - Lei das Diretrizes e Bases da Educação Nacional. http://www.planalto.gov.br/ccivil_03/leis/19394.htm.

Libãneo. J. C. (2013). O Planejamento Escolar. http://www.aecep.com.br/artigo/o-planejamento-escolar--jose-carlos-libaneo.html.

Marconi, M. de A., \& Lakatos, E. M. (2004). Metodologia científica. Editora Atlas.

Mariani, F. (2009). A formação de professores na perspectiva da educação emancipadora de Paulo Freire. https://educere.bruc.com.br/arquivo/pd f2009/2625 -1294.pdf.

Minayo, M. C. de S. (Org.). (2012). Pesquisa social: teoria, método e criatividade. (32a ed.), Vozes. (Coleção Temas Sociais).

Moraes, R., \& Galiazzi, M. (2006). Análise textual discursiva: processo reconstrutivo de múltiplas faces. Ciência \& Educação, 12 (1), $117-128$.

Moran, J. M. (2015). Mudando a educação com metodologias ativas. In Convergências Midiáticas, Educação e Cidadania: aproximações jovens. Coleção Mídias Contemporâneas. Disponível em http://www2.eca.usp.br/moran/wpcontent/uploads/2013/12/mudando_moran.pdf.

Nóvoa, A. (2018). Para uma formação de professores construída dentro da profissão. Universidad de Lisboa. Facultad de Psicología y Ciencias de la Educación. Lisboa, Portugal. https://docero.com.br/doc/scexxe.

Pereira, A. S. Shitsuka, D. M., Parreira, F. J., \& Shitsuka, R. (2018). Metodologia da pesquisa científica. UFSM. 
Research, Society and Development, v. 10, n. 12, e71101220134, 2021

(CC BY 4.0) | ISSN 2525-3409 | DOI: http://dx.doi.org/10.33448/rsd-v10i12.20134

Perrenoud, P. (2000). 10 Novas Competências para Ensinar: convite à viagem. Trad. Patrícia Chittoni Ramos. Artmed.

Santos. B. S. (2009). Revista de Direitos Humanos. http://www.boaventuradesousasantos.pt/media/Direitos\%20Humanos_Revista\%20Direitos\%2 0Huma nos2009.pdf.

Silveira, D. P.; Lorenzetti. L.; Scheffer, D. C. D; Golle, D. P. (2021). Diálogos sobre educação ambiental com escolares: um enfoque na educação ambiental crítica. Research, Society and Development. 10(3), e37110313558.

Vasconcellos, M.; Santiago, M. (2018, jan./abri.). Grupo de pesquisa “formar": inovação ou reinvenção de saberes? Revista Educação e Fronteiras On-Line, 8(22), 35-46. 